Ferreira, M. T. (2014). Las nociones de trabajo informal y trabajo precario en el análisis de la calidad del empleo en Colombia. Revista Lebret (6), Bucaramanga, Colombia: Universidad Santo Tomás, pp. 29-58. ISSN: 2145-5996.

\title{
Las nociones de trabajo informal y trabajo precario en el análisis de la calidad del empleo en Colombia*
}

\section{Notions of informal employment and precarious work to address quality of employment in Colombia}

María Teresa Ferreira Sequeda

\begin{abstract}
Resumen
En este artículo se evalúa el concepto de informalidad en Colombia en cuanto a su precisión para proveer información relevante sobre calidad del trabajo; a la luz de conceptos multidimensionales sobre empleo precario y seguridad laboral. Los resultados demuestran que la definición y medición del empleo informal vigentes en Colombia siguen siendo insuficientes para revelar las dificultades que enfrentan los trabajadores en términos de precariedad. Este trabajo propone una adaptación conceptual y operativa de la precariedad. Los resultados sugieren que los principales déficits en seguridad laboral que afronta la fuerza de trabajo colombiana son en materia de participación colectiva, protección contra riesgos laborales, prestaciones laborales y provisión de pensiones. Este estudio concluye que la informalidad no refleja la amplia heterogeneidad del trabajo precario en Colombia, ya que este último traspasa las fronteras sectoriales y ocupacionales de lo formal-informal, como ha sugerido recientemente el debate académico.
\end{abstract}

Palabras clave

Inseguridad laboral, precariedad laboral, empleo informal, sector informal, calidad del empleo.

Códigos de clasificación JEL: O17, J28, J81.

\begin{abstract}
In this article the concept of informality in Colombia is evaluated as to its accuracy to provide relevant information on job quality; in the light of multidimensional concepts of precarious employment and job security. The results show that the definition and measurement of informal employment taking place in Colombia remain insufficient to reveal the difficulties workers face in terms of precariousness. This paper proposes a conceptual and operational adaptation of precariousness. The results suggest that the main deficits on job security faced by the Colombian work force are in collective participation, protection against occupational hazards, employee benefits and pension provision. This study concludes that informality does not reflect the wide diversity of precarious work in Colombia, as the latter crosses sector and occupational boundaries of the formal-informal, as recently suggested by the academic debate.
\end{abstract}

\section{Keywords}

Job insecurity, precarious job, informal employment, informal sector job quality

Este artículo es resultado de la investigación "Informal employment and precarious work: concepts and statistics to approach quality of labour in Colombia" presentada como tesis del programa de Maestría en Estudios del Desarrollo, en International Institute of Social Studies (ISS), Universidad Erasmo de Rotterdam, Países Bajos.

1 Magíster en Estudios del Desarrollo. Estudiante del Doctorado en Economía, Universidad de Maastricht, Países Bajos. Profesora de la Escuela de Economía de la Universidad Industrial de Santander, Bucaramanga, Colombia. Correo electrónico: mferrer@uis.edu.co 


\section{Introducción}

Las teorías de la modernización presentan el crecimiento económico como el primer generador de la transición del empleo informal al empleo formal, este último asociado a mayor productividad y mejor protección social. Sin embargo, la experiencia de América Latina ha mostrado que a pesar del progreso económico, las principales estructuras del mercado laboral no se han transformado. La economía y la ocupación informal siguen siendo fundamentales; el empleo formal no ha aumentado y, al contrario, se han incrementado el desempleo y la informalidad (OIT, 2013a; 2006, p. 3).

Entre los países en desarrollo, Colombia es uno de los casos más relevantes por haber experimentado recientemente alto crecimiento del producto interno bruto (PIB) per cápita acompañado de persistentes altas tasas de trabajo informal ${ }^{2}$ (OIT, 2012; Cepal, 2011). Al mismo tiempo, otros problemas relacionados con la calidad del empleo se han profundizado, entre ellos el subempleo; el empleo temporal y subcontratado; protección social insuficiente; inseguridad y desigualdad de ingresos; y escasa representación y participación colectiva de los trabajadores ${ }^{3}$ (PGN, 2011; Biles, 2009).

Este artículo sostiene que los problemas del mercado de trabajo mencionados anteriormente no son directa ni satisfactoriamente capturados por el indicador de empleo en el sector informal en Colombia, el cual se ha convertido en la principal medida para monitorear el progreso/detrimento de la calidad del trabajo y en el foco para la formulación de políticas en el país (PGN, 2011; Botero, 2011; Pineda, 2008).

En la literatura, la tradicional dicotomía formal-informal ha comenzado a ser cuestionada. Tal como lo reportan Williams y Nadin (2012), varios estudios de casos e investigaciones cualitativas han descubierto que no todo el empleo formal es superior y tampoco las actividades económicas informales son necesariamente siempre inferiores. De otro lado, desde una perspectiva sociológica de las redes institucionales Taylor (2004) propone un marco conceptual para entender el trabajo como un continuo de prácticas laborales que trascienden la categorización de

2 En Colombia, el empleo informal ha aumentado del 45.7\% en 1990 a 59.6\% en 2010, en el que la proporción de trabajo por cuenta propia ha aumentado del $34 \%$ a $63 \%$ durante el mismo período.

3 La sindicalización y organización colectiva de trabajadores es uno de los riesgos laborales más mencionados sobre Colombia. De acuerdo con las cifras oficiales del Sistema de Información de Trabajo y Sindicalismo, la densidad sindical se redujo del 13\% en 1970 a menos del 4\% en 2012. Además, según la encuesta de violaciones de los derechos sindicales de la International Trade Union Confederation (2014), se ha producido un importante número de casos registrados de violación y restricción de los derechos sindicales en Colombia. Estos casos incluyen restricciones para unirse y organizar sindicatos; restricciones al principio de la negociación libre y voluntaria; violación de los convenios colectivos; limitaciones o prohibición de hacer huelga en algunos sectores; despidos y sanciones civiles o penales para los trabajadores que han participado en acciones de huelga, despidos de dirigentes sindicales, acoso antisindical y discriminación; y amenazas de muerte, intentos de asesinato y asesinato de líderes sindicales. Según esta fuente, de 2002 a 2010, los tribunales colombianos registraron 296 sentencias por crímenes contra sindicalistas con 414 víctimas. 
empleo formal/informal. Más recientemente, la OIT (2013b) también ha reconocido las limitaciones de la sistematización formal/informal del empleo para describir la complejidad del mundo del trabajo. En este informe, la OIT llama la atención sobre la necesidad de revisar las guías estadísticas vigentes, con el fin de componer medidas más integrales que diluciden las nuevas dinámicas de trabajo, tanto dentro como fuera del ámbito informal.

Todo esto plantea serios interrogantes sobre la precisión de la noción de informalidad, tal como se aplica en Colombia, para revelar los problemas de calidad del empleo. Como sostienen Yusuff (2011) y Habib-Mintz (2009), los enfoques teóricos existentes de la informalidad son inadecuados para abordar la diversidad y el dinamismo del trabajo formal/informal en los países en desarrollo. Puede existir un segmento significativo de trabajadores formales que mantienen empleos de baja calidad debido a la interacción entre el riesgo de desempleo y el deterioro de la seguridad en el empleo; y algunos otros considerados trabajadores informales, que pueden tener de alguna manera trabajos de buena calidad (Tucker, 2002).

Este reconocimiento marca el punto de partida de un debate acerca de lo que significa un trabajo de calidad para adoptar nuevos conceptos y estadísticas más avanzadas en lugar de asumir un enfoque de "talla única" sobre la formalidad/ informalidad del trabajo (Williams y Nadin, 2012, p. 7). Lo anterior motiva la introducción de la noción de trabajo precario (en adelante TP) como lente riguroso alternativo para identificar aquellas ambigüedades conceptuales y estadísticas relacionadas con la calidad del empleo en un país en desarrollo. En esa línea de ideas, las preguntas de investigación de este artículo son: i) ¿En qué medida los conceptos de informalidad, tal como se aplican en Colombia, abordan con precisión los problemas de la calidad del trabajo?; y ii) ¿En qué sentido es el trabajo precario una mejor alternativa para comprender, medir e informar mejor a la política sobre la calidad del trabajo?

Este trabajo contribuye a la literatura proporcionando evidencia empírica a la discusión sobre las debilidades de la dicotomía formal/informal en el contexto de un país en desarrollo. En lugar de dicha dicotomía, este artículo propone un índice continuo para captar la calidad del empleo en términos de precariedad en todas las formas de trabajo. Para ello, el artículo se divide en seis secciones. Partiendo de los enfoques más relevantes sobre la informalidad, la sección segunda estudia críticamente la definición y puesta en práctica de dichas nociones en el contexto colombiano. La sección tercera presenta el marco conceptual sobre precariedad para sugerir una adaptación de este concepto al caso colombiano. En la sección cuarta se desarrolla la definición y diseño de un índice multidimensional de TP a nivel individual, cuyos resultados para el caso colombiano son presentados en la sección quinta. Finalmente, la sección sexta concluye y examina algunas implicaciones de política. 


\section{Conceptos y medición del trabajo informal}

\section{Perspectivas teóricas}

Cuatro escuelas de pensamiento son bien conocidas en la literatura sobre la informalidad: la escuela dualista, la escuela estructuralista, la escuela legalista y el enfoque integrado. En primer lugar, la escuela dualista presenta la informalidad como el sector inferior de un mercado de trabajo dual, donde los trabajadores (en general no cualificados) subsisten temporalmente gracias a su participación en actividades de baja productividad. El sector informal es, entonces, un sector residual que surge del proceso de transformación en una economía en desarrollo que no puede absorber una parte de su fuerza laboral. Sin embargo, se espera que el sector informal sea totalmente absorbido por el sector formal en el largo plazo gracias al crecimiento económico (Arnold y Bongiovi, 2012; Fields, 1990).

En segundo lugar, la perspectiva estructuralista enfatiza las conexiones productivas entre los sectores formal e informal, vinculados a través de la producción globalizada y las cadenas de insumos. El sector informal es visto como subordinado a las grandes empresas capitalistas que suministran mano de obra barata a estas últimas debido a fuertes incentivos generados por la demanda y el crecimiento (Arnold y Bongiovi, 2012; Yusuff, 2011; Chen, 2007). Sin embargo, los estructuralistas reconocen que esta dinámica entre el trabajo informal y el progreso económico ocurren a costa de la explotación laboral. Por lo tanto, el crecimiento económico no es suficiente para erradicar las relaciones de producción informales y la intervención del gobierno es esencial para combatir la extensión de la informalidad laboral y proporcionar protección jurídica a los trabajadores (Portes citado en Habib-Mintz, 2009, pp. 7-8).

En tercer lugar, el enfoque legalista presenta el sector informal como un conjunto de micro-empresarios que prefieren operar de manera informal para evitar los costos asociados con el registro. En contraste con los dos previos, esta visión legalista apunta a la naturaleza voluntaria de la informalidad. Como tal, las actividades en el sector informal pueden ser eficientes y rentables y, por lo tanto, constituyen un potencial para el crecimiento económico y la mejora en los estándares de vida, si las reformas regulatorias y las reducciones fiscales son introducidas (Yusuff, 2011; De Soto, 1989).

Por último, el enfoque integrado combina elementos de los tres enfoques anteriores, basados en la idea de los mercados de trabajo multi-segmentados (Chen, 2007). En palabras de Bacchetta et al. (2009, p. 45)

La economía informal es la suma de diferentes segmentos y diferentes tipos de agentes: un segmento de nivel inferior dominado por los hogares que participan en actividades de supervivencia con pocos vínculos con la economía formal, como los dualistas sugieren; un segmento de nivel superior con micro-empresarios que optan por evitar los impuestos y regulaciones, 
como los legalistas sugieren; y un segmento intermedio con micro-empresas y trabajadores subordinados a las grandes empresas, según lo sugerido por los estructuralistas.

\section{Definición y medición}

La Organización Internacional del Trabajo (OIT) introdujo originalmente en la década de 1970 el concepto de sector informal como aquel sector de la economía compuesto por empresas privadas no registradas que normalmente operan en pequeña escala y con trabajo informal. En 2002, la OIT amplió dicha definición e introdujo el concepto de economía informal para definir "todas las actividades económicas de los trabajadores y las unidades económicas que-legalmente o en la práctica-no están cubiertas o están insuficientemente cubiertas por las disposiciones institucionales formales" (OIT, 2002, p. 5). La implicación más importante de esta última definición es que el empleo informal puede existir tanto en el sector informal como en el formal (OIT, 2013a, p. 37; 2002, p. 6).

Las directrices de la OIT para la medición de la economía informal, desarrolladas por Hussmanns (2004), reconocen que dicha definición es muy difícil de poner en práctica. No obstante, utilizando un enfoque de bloques, es posible desagregar el empleo total en función de dos dimensiones: i) tipo de unidad de producción (formal, informal u hogares), y ii) tipo de empleo (formal, informal) determinado básicamente en función de las categorías de ocupación laboral (OIT, 2013a). Esto significa que los trabajadores informales son estadísticamente identificados con base en su posición ocupacional y el carácter formal/informal del establecimiento empleador (Hussmanns, 2004, p. 6).

Con todo, esta técnica de medición resulta limitada para revelar la transversalidad entre el empleo informal y el sector informal, principalmente por dos razones. En primer lugar, ningún otro criterio diferente al del tamaño de la empresa está disponible en las encuestas de hogares para definir la formalidad de los establecimientos empleadores en muchos países en desarrollo (Hussmanns, 2004, p. 6). Por consiguiente, la identificación del tipo de unidad productiva se fundamenta en el supuesto neoclásico del vínculo directo entre el tamaño de la firma y su productividad. En segundo lugar, como argumenta Sindzingre (2006, pp. 4-7), la predeterminación de empleos formales/informales basada en categorías ocupacionales no se centra en los atributos inherentes al trabajo y, por tanto, no hace distinción sustantiva entre las formas institucionales y contenidos que explican con mayor precisión la dinámica de las actividades informales. Se podría decir, entonces, que la posición ocupacional, el tamaño del establecimiento y los criterios de legalidad de la firma afirman aquella presunción dualista de empleos formales de buena calidad y trabajos informales de baja calidad. Por definición, mantenerse fuera de las estructuras jurídicas e instituciones formales de la economía moderna sigue 
siendo considerada la característica responsable de la natural baja calidad del empleo informal (OIT, 2013a, p. 4).

Esto quiere decir que la identificación de la informalidad, basada en la metodología de la OIT, es aún restringida para reflejar la compleja realidad del empleo informal de una manera consistente con diversos niveles de calidad de las condiciones laborales que van más allá de los aspectos legalistas, el tamaño de la empresa y la categoría ocupacional de los trabajadores. Esto restringe el análisis de la heterogeneidad dentro del mercado laboral formal-informal en los países en desarrollo, como se argumenta más adelante para el caso colombiano.

\section{Medición de la informalidad en Colombia}

El Departamento Administrativo Nacional de Estadística - DANE comenzó a medir la informalidad en 1987. La metodología vigente adoptó el marco internacional de la OIT sobre el uso de los criterios de organización jurídica (tamaño de la empresa) sobre estadísticas del sector informal (DANE, 2009).

La informalidad se mide en Colombia como la suma de los trabajadores en actividades no agrícolas en las siguientes posiciones ocupacionales: i) empleados particulares y obreros que laboran en establecimientos que ocupan hasta cinco trabajadores; ii) trabajadores sin remuneración; iii) empleados domésticos; iv) jornaleros o peones; v) trabajadores por cuenta propia que laboran en establecimientos de hasta cinco trabajadores, con excepción de profesionales independientes; y vi) empleadores en empresas de cinco o menos trabajadores. Todos los obreros o empleados del gobierno se excluyen.

Lo anterior indica que el DANE mide en realidad solo la proporción de empleo en el sector informal. El indicador oficial de informalidad en Colombia está por lo tanto desactualizado, ya que no capta la distinción entre el empleo en la economía formal e informal introducido por la OIT en 2002. Aunque los datos permitirían estos cálculos, en la forma sugerida por Hussmanns (2004), como se muestra en la tabla 1 , este tipo de análisis aún no ha sido considerado por las autoridades nacionales. La consecuencia es que los conceptos que se refieren a diferentes aspectos de la informalización del empleo corresponden a diferentes objetivos para la formulación de políticas (OIT, 2013a) no se han tenido en cuenta por el Gobierno nacional. La siguiente sección desarrolla esta idea. 
Tabla 1. Empleo en la economía formal e informal, Colombia 2010

\begin{tabular}{|lccccc|}
\hline \% empleo no-agrícola & Total & Mujeres & Hombres & Urbano & Rural \\
\hline Personas en empleo informal & 59.6 & 62.7 & 57.0 & 57.6 & 78.9 \\
\hline $\begin{array}{l}\text { Personas empleadas en el sector informal } \\
\text { Personas en empleo formal, empleadas en el sector }\end{array}$ & 52.1 & 51.2 & 53.1 & 50.3 & 69.5 \\
$\begin{array}{l}\text { formal } \\
\begin{array}{l}\text { Personas en empleo informal, empleadas fuera del } \\
\text { sector informal }\end{array}\end{array}$ & 9.3 & 1.5 & 2.0 & 1.8 & 1.5 \\
\hline
\end{tabular}

Fuente: OIT, 2012.

\section{Implicaciones políticas en el ámbito nacional}

En Colombia, la informalidad se define oficialmente como "el conjunto de actividades económicas que ignoran las leyes comerciales, laborales y/o fiscales" (CPC, 2010, p. 132). Según el Gobierno, la informalidad es una de las principales barreras para el crecimiento del PIB, la productividad y la competitividad. La informalidad implica una asignación ineficiente de los recursos humanos en actividades de bajo retorno y, por lo tanto, baja calidad del empleo; todo ello considerado como el principal problema para las personas pobres en el país (DNP, 2011, p. 101; CPC, 2010, pp. 78-80).

Esto refleja que la preocupación por la calidad del empleo en Colombia ha sido subordinada a la discusión sobre la competitividad y el crecimiento económico. Desde una interpretación dualista de la informalidad, el Gobierno piensa que "existe una relación bidireccional entre el sector formal y el empleo formal, y la productividad", al mismo tiempo que "la formalización asegura la creación de empleos de calidad decentes" (CPC, 2010, p. 2). Como resultado, la reducción de la informalidad es un objetivo político indirecto, crucial para la modernización y la globalización de la economía colombiana (DNP, 2011; CPC, 2010).

Como señalan Uribe y Ortiz (citados en Pineda, 2008, p. 13), el supuesto detrás de esta idea viene de la teoría neoclásica de las economías de escala, el cual establece una relación positiva entre el tamaño y la productividad de la empresa. Con base en teorías de la modernización, las autoridades nacionales confían en que el crecimiento económico lidere la transición hacia el empleo productivo formal.

La consecuencia es un proceso de formulación de políticas equívocas respecto a la calidad del empleo. Por ejemplo, el Banco Central de Colombia (2011, p. 12) afirma en uno de sus últimos informes que:

A pesar de los avances en la reducción del desempleo, la calidad y la estabilidad en el empleo siguen siendo débiles, como lo indica el alto nivel de informalidad, y la elevada proporción de empleo por cuenta propia (...) Sin embargo, con base 
en las expectativas positivas sobre el futuro desempeño económico, se espera que mejore la calidad del empleo a través de la generación y formalización de empleos en el sector moderno de la economía.

Ese vínculo directo que se establece entre una mejor calidad del empleo, el sector formal, la gran empresa y el crecimiento económico constituye una de las principales limitaciones de la conceptualización y medición de la calidad del trabajo a través de la informalidad. La noción de informalidad en Colombia está no solamente desactualizada sino también erróneamente canalizada en términos de política. En primer lugar porque la distinción entre el empleo en la economía formal e informal es ignorada. En segundo lugar porque la conceptualización y medición de la informalidad son muy imprecisas para revelar objetivamente otras dimensiones de la calidad del trabajo, tales como las condiciones laborales, oportunidades de progreso, estabilidad y organización colectiva, entre otros. Así entonces, estos desafíos a la calidad del empleo escapan también al diseño de políticas.

El problema de la interpretación de la calidad del empleo a través de la definición de la (in)formalidad "puede ser engañosa y no necesariamente nos dice algo acerca de lo que queremos saber: la calidad de los puestos de trabajo en una economía" (Kucera y Roncolato, 2008, p. 329). Para hacer del empleo informal un concepto más significativo, es imprescindible analizar la calidad de este empleo, así como la del empleo formal, de una manera explícita y objetiva. La noción de "trabajo precario", cuyo énfasis son las diferentes formas de (in)seguridad laboral puede ofrecer una alternativa para abordar la calidad del trabajo a través de dimensiones más amplias y objetivas.

\section{El concepto de precariedad}

La noción de empleo precario apareció en Europa en la década de 1970, cuando los contratos de duración determinada comenzaron a surgir. El término fue inicialmente relacionado con las formas de empleo que carecen de la seguridad laboral asociada tradicionalmente con el contrato formal y estándar de duración indefinida (Barbier, 2002). Más recientemente se han desarrollado otros conceptos multidimensionales de la precariedad, los cuales argumentan que el TP no puede considerarse idéntico al empleo no estándar, aunque a menudo están correlacionados. Formas de empleo estándar, por lo general asociadas al empleo formal, pueden implicar relaciones de trabajo de calidad variable, algunas de las cuales pueden contener elementos de precariedad (Vosko y Clark, 2009).

\section{Conceptos y dimensiones}

Rodgers y Rodgers (1989) argumentan que la precariedad va más allá de la posición ocupacional de los trabajadores. De acuerdo con estos autores, el trabajo precario se caracteriza por la escasa seguridad en las siguientes cuatro dimensiones, 
lo cual expone al trabajador a diversos grados de inseguridad laboral y vulnerabilidad socioeconómica:

i) Temporal: duración limitada o incertidumbre respecto de la continuidad del empleo.

ii) Organizacional: débil control individual y colectivo sobre las condiciones de trabajo.

iii) Protección: beneficios reducidos de seguridad social y escasa protección ante condiciones de trabajo inadecuadas.

iv) Económico: salario insuficiente y escasas oportunidades para la progresión salarial, asociados generalmente a la pobreza y la exclusión social.

Del mismo modo, Standing (2011) presenta una versión multidimensional de las formas de trabajo relacionadas con la (in)seguridad, con base en estudios de la OIT (2004) y Standing (1999). En esta conceptualización de la precariedad, los ingresos y la representación colectiva de los trabajadores son considerados primordiales y merecen tenerse en cuenta como dimensiones separadas, como sigue:

i) Seguridad del mercado laboral: oportunidades de empleo suficientes y satisfactorias.

ii) Seguridad del empleo: protección y regulación sobre contratación, despido, entre otros.

iii) Seguridad laboral: oportunidades de progreso en la carrera laboral y control sobre las condiciones de trabajo.

iv) Seguridad en el trabajo: seguridad y protección social, y condiciones de trabajo seguras y saludables.

v) Seguridad de formación profesional: oportunidades para retener y adquirir nuevas habilidades y conocimientos.

vi) Seguridad de los ingresos: ingresos adecuados y protección de estos, regulación sobre salarios mínimos e indexación salarial.

vii) Seguridad de representación: derechos efectivos participación y representación colectiva.

Estos enfoques sugieren que el TP constituye empleo de baja calidad caracterizado por carencias de seguridad laboral multidimensional que exponen a los trabajadores a diferentes grados de riesgo (Standing, 2011; Vosko, 2006; OIT, 2004). A su vez, Vosko et al. (2009) hacen especial hincapié en que la precariedad es una noción que incluye todo tipo de trabajadores, independientemente de su situación laboral o posición ocupacional. Este enfoque multidimensional del TP es una alternativa que intenta abarcar toda una gama de atributos asociados a la calidad del trabajo en 
términos de seguridad, de manera que dilucida los distintos grados y formas en que dicha calidad puede verse amenazada.

Por consiguiente, el trabajo precario "es empleo que puede encontrarse tanto en la economía formal como informal, caracterizado por distintos niveles objetivos de incertidumbre e inseguridad (...) y derechos sindicales particularmente insuficientes" (OIT, 2012b, p. 27). Por tanto, puede haber un número de puestos de trabajo formales en situación de precariedad en uno o más aspectos, y algunos otros trabajos informales que podrían alcanzar en algún grado condiciones de buena calidad; sin embargo, no incluidos ni explorados en las estadísticas estándares (Tucker, 2002; Comisión Europea, 2004).

\section{Identificación de los trabajadores precarios}

Dado que no existe una correspondencia directa entre posición ocupacional y trabajo precario, la OIT (2012b, p. 28) ha señalado la necesidad de identificar los elementos clave de la precariedad con el objeto de establecer algunas pautas generales de medición. En esta publicación de 2012, la OIT inicialmente se concentró en el empleo temporal (contratos de duración determinada y trabajo subcontratado), que han sido relacionadas con el crecimiento de la precariedad en Europa.

Teniendo en cuenta el concepto de precariedad multidimensional propuesta por Rodgers y Rodgers (1989) y Standing (2011), un enfoque unidimensional no solo es limitado, sino también inadecuado para el caso de los países en desarrollo. Dado que en América Latina el porcentaje de asalariados apenas supera el cincuenta por ciento de la población activa -debido a la gran proporción de trabajo por cuenta propia ${ }^{4}$ (Cepal, 2011)-, la identificación de la precariedad laboral basada únicamente en el tipo de contrato de trabajo dejaría por fuera del análisis un segmento muy importante de la población activa.

Un estudio que identifica el TP desde una perspectiva multidimensional es McKay et al. (2012). A través de entrevistas cualitativas, cuestionarios y estudios de caso, estos autores exploraron distintas percepciones del trabajo precario entre 484 actores del mercado laboral en 12 países europeos. A pesar de que el trabajo asalariado permanente sigue siendo la forma predominante de empleo en Europa, este análisis considera variedad de relaciones de trabajo no estándar. Los resultados cuantitativos muestran cálculos promedio de valoración emitidos por los distintos actores en cada categoría ocupacional con respecto de diferentes derechos y riesgos laborales ${ }^{5}$. McKay et al. (2012) proporcionan dichos resultados en una escala de cinco

4 En Colombia, el trabajo independiente alcanzó el 40,1\% del empleo total en 2011, mientras que solo el 30\% de los asalariados tenían un contrato escrito (no verbal).

5 Se incluyen la seguridad en el lugar de trabajo, duración de las relaciones contractuales, intensidad horaria, discriminación, protección y seguridad social, pensiones, estabilidad, bienestar, oportunidades de formación, salario digno, salud y seguridad, representación colectiva, entre otros aspectos. 
puntos. Los resultados señalan que la situación más precaria del trabajo corresponde a la incapacidad individual de los trabajadores para hacer valer sus derechos, en especial la ausencia o dificultad para acceder a la representación y la negociación colectiva. Las siguientes situaciones que se encontraron más precarias son en su orden: escasa seguridad social, altos riesgos de salud y seguridad en el lugar de trabajo, e insuficiencia de ingresos.

\section{Definición para el contexto colombiano}

\section{Punto de referencia}

La Constitución de Colombia (1991, artículos 53 y 55) establece que el Estatuto de Trabajo, en correspondencia con las normas laborales ratificadas ante la OIT, debe garantizar por lo menos los siguientes principios mínimos fundamentales:

Igualdad de oportunidades para los trabajadores; remuneración mínima vital y móvil, proporcional a la cantidad y calidad del trabajo; estabilidad en el empleo; irrenunciabilidad a los beneficios mínimos establecidos en normas laborales; facultades para transigir y conciliar sobre derechos inciertos y discutibles; favorabilidad al trabajador en caso de duda en la aplicación e interpretación de las fuentes formales de derecho; primacía de la realidad sobre formalidades establecidas por los sujetos de las relaciones laborales; garantía a la seguridad social, capacitación, formación y descanso necesario; y la protección especial a la mujer, la maternidad y al trabajador menor de edad. El Estado garantiza el derecho al pago oportuno y al reajuste periódico de las pensiones legales (...) Se garantiza el derecho de negociación colectiva para regular las relaciones laborales, con las excepciones que señale la ley. Es deber del Estado promover la concertación y los demás medios para la solución pacífica de los conflictos colectivos de trabajo.

\section{Definición}

En este artículo, el TP es entendido como el empleo de baja calidad que abarca múltiples aspectos que afectan tanto a la relación laboral como a las condiciones de trabajo en sí. Una definición multidimensional del TP debe contemplar no menos que los atributos constitucionales de seguridad laboral mencionados anteriormente, en el contexto de las dimensiones presentadas por Rodgers y Rodgers (1989), la OIT (2004) y Standing (2011), en las cuales se destacan la seguridad de los ingresos y la seguridad de representación colectiva, dimensiones particulares y separadas. A la luz de todo lo anterior, la definición de precariedad en este trabajo refiere a los trabajadores que están expuestos a uno o más déficits en las cinco dimensiones que se presentan en la figura 1 . 
Figura 1. Dimensiones del trabajo precario para el caso colombiano

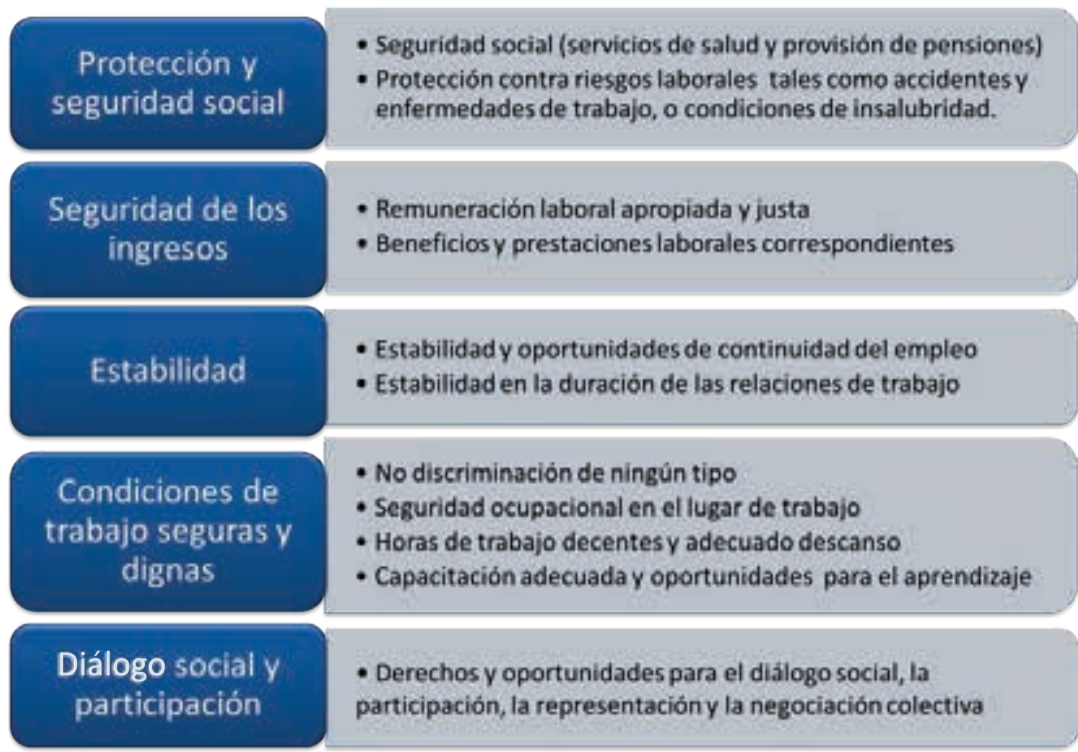

Fuente: autora.

Estas cinco dimensiones están vinculadas a los siguientes riesgos: i) falta de protección social suficiente; ii) inestabilidad de la trayectoria laboral; iii) bajos ingresos y privación de los beneficios y prestaciones laborales; iv) falta de protección frente a ambientes físicos de trabajo desfavorables; y (v) escasez de libertad de asociación, expresión, participación y negociación colectiva. Estos riesgos indican que el problema del trabajo precario no se define como una característica exclusiva de la economía o el trabajo informal, al mismo tiempo que la buena calidad del empleo no es una propiedad exclusiva de empleos formales. El enfoque propuesto permite evaluar analíticamente las dimensiones mencionadas para ser tratadas como características analíticas que son relevantes para todas las formas de trabajo.

\section{Operacionalización de la precariedad laboral en Colombia}

\section{Diseño}

El concepto de precariedad laboral descrito anteriormente es operacionalizado mediante un índice compuesto, denominado Índice de Trabajo Precario (ITP). Este mide en promedio para cada trabajador la calidad de su empleo individual con base en las cinco dimensiones descritas en la figura 1. 
El índice compuesto ITP se define como:

$$
\operatorname{ITP}_{i}=\sum \mathrm{w}_{i} \mathbf{x}_{i j}(1)
$$

donde $\mathrm{ITP}_{i}$ es el índice compuesto para el $\mathrm{i}^{\mathrm{s} s i m o}$ individuo, $\mathrm{w}_{\mathrm{i}}$ es el peso asignado al $\mathrm{i}^{\mathrm{éssimo}}$ indicador $\mathrm{y}_{\mathrm{ij}}$ es el valor de la ísima variable en la jésima dimensión.

Por lo tanto, el ITP mide la precariedad como un continuo y no como una dicotomía. No asume correspondencia directa entre ninguna posición ocupacional específica y precariedad; lo importante es la intersección y combinación de las diversas dimensiones de precariedad laboral.

\section{Datos}

Este estudio utilizó microdatos de la Gran Encuesta Integrada de Hogares (GEIH) realizada en 2011 por el DANE en Colombia. La muestra estuvo conformada por todos los individuos ocupados (cuenta propia y asalariados) para un total de 23667 observaciones; 21257 de las zonas urbanas y 2410 de las zonas rurales.

El principal obstáculo para la operacionalización de este índice fue la falta de datos. En primer lugar, la escasa representación de trabajadores rurales limita la identificación de la precariedad rural. En segundolugar, la encuesta carece de preguntas para identificar la incidencia de accidentes o enfermedades laborales, discriminación en el trabajo, participación en programas de capacitación o aprendizaje, interés para afiliarse a sindicatos o asociaciones de trabajo, cobertura de los convenios colectivos, y evolución de los ingresos. Además, existe un déficit cualitativo en la información, especialmente respecto a la protección social y asociación laboral. En consecuencia, los indicadores respectivos incluidos se restringen a criterios de registro o asociación más no al acceso efectivo en las dimensiones mencionadas.

\section{Dimensiones y variables}

Con base en la información disponible en la GEIH, la operacionalización del ITP en Colombia resultó en el conjunto de nueve variables que se presenta a continuación en la tabla 2 . 
Tabla 2. Dimensiones y variables de trabajo precario: el caso colombiano

\begin{tabular}{|c|c|c|c|}
\hline Dimensión & Variable & Preguntas GEIH & Criterio \\
\hline \multirow{3}{*}{$\begin{array}{l}\text { 1. Seguridad } \\
\text { y protección } \\
\text { social }\end{array}$} & $\begin{array}{l}\text { 1. Seguro de } \\
\text { salud }\end{array}$ & $\begin{array}{l}\text { i) ¿Está afiliado, es } \\
\text { cotizante o es beneficiario } \\
\text { de alguna entidad de } \\
\text { seguridad social en salud? }\end{array}$ & Derecho constitucional. \\
\hline & $\begin{array}{l}\text { 2. Provisión de } \\
\text { pensiones }\end{array}$ & $\begin{array}{l}\text { i) ¿Está cotizando } \\
\text { actualmente a un fondo de } \\
\text { pensiones? } \\
\text { ii) ¿Qué está haciendo } \\
\text { usted para obtener } \\
\text { recursos en caso de } \\
\text { jubilación o para la vejez? }\end{array}$ & $\begin{array}{l}\text { El Código Sustantivo } \text { del } \\
\text { Trabajo en Colombia (CST, } \\
2006 \text { ) establece para los } \\
\text { trabajadores asalariados una } \\
\text { contribución de } 16 \% \text { del salario } \\
\text { mensual al sistema de pensiones. } \\
\text { Además, este indicador valora } \\
\text { positivamente los casos de } \\
\text { trabajadores no asalariados que } \\
\text { no contribuyen al sistema de } \\
\text { pensiones, pero están } \\
\text { proveyendo recursos de otras } \\
\text { maneras para la jubilación. }\end{array}$ \\
\hline & $\begin{array}{l}\text { 3. Seguro de } \\
\text { riesgos laborales }\end{array}$ & $\begin{array}{l}\text { i) ¿Está afiliado por una } \\
\text { empresa o individualmente } \\
\text { a una aseguradora de } \\
\text { riesgos profesionales } \\
\text { (ARP) (por accidentes de } \\
\text { trabajo, enfermedad } \\
\text { profesional, entre otros)? }\end{array}$ & $\begin{array}{l}\text { El CST (2006) establece que } \\
\text { todos los trabajadores deben } \\
\text { tener un seguro de riesgos } \\
\text { laborales para protegerlos de } \\
\text { accidentes o enfermedades de } \\
\text { trabajo. }\end{array}$ \\
\hline $\begin{array}{l}\text { 2. Seguridad } \\
\text { de los } \\
\text { ingresos }\end{array}$ & $\begin{array}{l}\text { 1. Ingresos } \\
\text { laborales }\end{array}$ & $\begin{array}{l}\text { i) Ingreso laboral mensual } \\
\text { total }\end{array}$ & $\begin{array}{l}\text { Convenios de la OIT ratificados } \\
(26,95,99,100) \text { con respecto a } \\
\text { los salarios mínimos (SM) y la } \\
\text { igualdad de remuneración. } \\
\text { Este indicador se calcula en } \\
\text { concordancia con los SM por } \\
\text { niveles de educación. El SM } \\
\text { legal fijado por el Gobierno se } \\
\text { toma como punto de referencia } \\
\text { para los trabajadores no } \\
\text { cualificados. El SM para los } \\
\text { trabajadores que tienen un mayor } \\
\text { nivel de educación se basa en la } \\
\text { escala de SM publicada por la } \\
\text { Red SEIS de Educación Superior } \\
\text { en Colombia, la cual es validada } \\
\text { por el Observatorio del Trabajo } \\
\text { del Ministerio de Educación. }\end{array}$ \\
\hline
\end{tabular}




\begin{tabular}{|c|c|c|c|}
\hline Dimensión & Variable & Preguntas GEIH & Criterio \\
\hline & $\begin{array}{l}\text { 2. Beneficios y } \\
\text { prestaciones } \\
\text { laborales }\end{array}$ & $\begin{array}{l}\text { Para los trabajadores que } \\
\text { tienen un contrato: ¿Tiene } \\
\text { derecho a ... } \\
\text { i) Indemnización por } \\
\text { despido? } \\
\text { ii) Vacaciones } \\
\text { sueldo? con } \\
\text { iii) Subsidio de } \\
\text { transporte? (Si procede) }\end{array}$ & $\begin{array}{l}\text { De acuerdo con el CST (2006), } \\
\text { los trabajadores tienen derecho a } \\
\text { los siguientes beneficios: } \\
\text { i) Indemnización por despido: } \\
\text { un salario mensual por cada } \\
\text { año de servicio, más los } \\
\text { intereses. } \\
\text { ii) Vacaciones pagadas: quince } \\
\text { días laborales por cada año } \\
\text { de trabajo. } \\
\text { iii) Subsidio de transporte para } \\
\text { los empleados que ganan } \\
\text { hasta dos SMMV. } \\
\text { iv) Prima de servicios: quince } \\
\text { días de salario por cada } \\
\text { semestre laborado. Debido a } \\
\text { inconsistencia en los datos, } \\
\text { no se incluyó esta última } \\
\text { variable. } \\
\text { Para los trabajadores que no } \\
\text { tienen un contrato, se calculó el } \\
\text { valor monetario de los beneficios } \\
\text { aplicables para determinar sus } \\
\text { derechos. Para los trabajadores no } \\
\text { remunerados, el indicador toma el } \\
\text { valor de } 0 \text {. }\end{array}$ \\
\hline 3. Estabilidad & 1. Estabilidad & $\begin{array}{l}\text { i) ¿Cuánto tiempo lleva } \\
\text { (meses) trabajando en esta } \\
\text { empresa, negocio, } \\
\text { industria, oficina, firma o } \\
\text { finca de manera continua? } \\
\text { Para los trabajadores } \\
\text { asalariados: } \\
\text { ii) ¿Qué tipo de contrato } \\
\text { tiene para realizar este } \\
\text { trabajo? a. contrato verbal, } \\
\text { b. contrato a término fijo } \\
\text { (especificar la duración en } \\
\text { meses), c. contrato a } \\
\text { término indefinido. } \\
\text { Para los trabajadores } \\
\text { independientes y no } \\
\text { remunerados: } \\
\text { ii) ¿Este trabajo es } \\
\text { ocasional, estacional, o } \\
\text { permanente? }\end{array}$ & 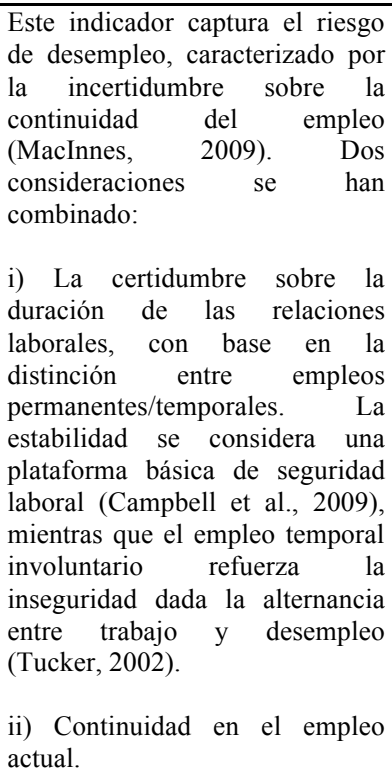 \\
\hline
\end{tabular}




\begin{tabular}{|c|c|c|c|}
\hline Dimensión & Variable & Preguntas GEIH & Criterio \\
\hline \multirow{2}{*}{$\begin{array}{l}\text { 4. Condiciones } \\
\text { de trabajo } \\
\text { seguras y } \\
\text { dignas }\end{array}$} & $\begin{array}{l}\text { 1. Seguridad en } \\
\text { el lugar de } \\
\text { trabajo }\end{array}$ & $\begin{array}{l}\text { i) ¿Dónde realiza } \\
\text { principalmente su } \\
\text { trabajo? } \\
\text { a. Propia u otras } \\
\text { vivienda } \\
\text { b. Quiosco, caseta o } \\
\text { vehículo } \\
\text { c. Puerta a puerta, o en } \\
\text { las calles } \\
\text { d. Lugar fijo (oficina, } \\
\text { fábrica, entre otros) } \\
\text { e. Campo o área rural, } \\
\text { mar o río } \\
\text { f. Construcción, minas o } \\
\text { canteras } \\
\text { ii) ¿Desea cambiar el } \\
\text { trabajo que tiene } \\
\text { actualmente por } \\
\text { problemas ambientales } \\
\text { (aire, olores, frío, ruidos, } \\
\text { temperatura, entre } \\
\text { otros)? }\end{array}$ & $\begin{array}{l}\text { Convenios de la OIT ratificados } \\
\text { (81, 129, 154, 167, 170 y 174) } \\
\text { sobre la inspección del trabajo, } \\
\text { la seguridad, la salud y la } \\
\text { prevención de accidentes de } \\
\text { trabajo. Además, el CST (2006) } \\
\text { precisa a los empleadores } \\
\text { proporcionar equipos y lugares } \\
\text { de trabajo que garanticen la } \\
\text { seguridad y salubridad de los } \\
\text { trabajadores. } \\
\text { Condiciones de baja calidad de } \\
\text { los lugares de trabajo están } \\
\text { asociadas con ocupaciones en } \\
\text { ambientes abiertos o al aire libre } \\
\text { o lugares fijos con problemas } \\
\text { ambientales, que generalmente } \\
\text { exponen a los trabajadores a un } \\
\text { alto } \\
\text { accidentes/enfermedades (Farné } \\
\text { et al., 2011). }\end{array}$ \\
\hline & $\begin{array}{l}\text { 2. Horas de } \\
\text { trabajo } \\
\text { semanales }\end{array}$ & $\begin{array}{l}\text { i) ¿Cuántas horas a la } \\
\text { semana trabaja } \\
\text { habitualmente en este } \\
\text { trabajo? } \\
\text { ii) ¿Por qué razón trabaja } \\
\text { usted menos de } 40 \text { horas } \\
\text { a la semana? a. Es lo } \\
\text { único que ha conseguido } \\
\text { pero quiere trabajar más } \\
\text { horas, b. Es la jornada } \\
\text { que se ajusta a sus } \\
\text { necesidades c. Otra. }\end{array}$ & $\begin{array}{l}\text { Convenios de la OIT ratificados } \\
\text { (1, 14, } 30 \text { y 106) sobre la carga } \\
\text { horaria laboral. El CST (2006) } \\
\text { establece un máximo de } 48 \\
\text { horas de trabajo por semana. } \\
\text { Este indicador obedece a los } \\
\text { siguientes principios: } \\
\text { i) Horas semanales más } \\
\text { próximas a la media de tiempo } \\
\text { completo (entre } 37 \text { y } 48 \\
\text { horas/semana), tienden a estar } \\
\text { asociadas a mayor seguridad } \\
\text { (MacInnes, 2009). } \\
\text { ii) Desviaciones por encima de } \\
\text { la media, es decir cargas } \\
\text { horarias excesivamente largas se } \\
\text { asocian a menor seguridad. } \\
\text { iii) Desviaciones por debajo de } \\
\text { la media, es decir, cargas } \\
\text { horarias demasiado cortas } \\
\text { (subempleo) se asocian a menor } \\
\text { seguridad, solo en los casos en } \\
\text { que este tipo de subempleo es } \\
\text { involuntario. }\end{array}$ \\
\hline
\end{tabular}




\begin{tabular}{|c|c|c|c|}
\hline Dimensión & Variable & Preguntas GEIH & Criterio \\
\hline $\begin{array}{c}\text { 5. Diálogo } \\
\text { social y } \\
\text { participación }\end{array}$ & $\begin{array}{l}\text { 1. Asociación } \\
\text { laboral o } \\
\text { afiliación } \\
\text { sindical }\end{array}$ & $\begin{array}{l}\text { i) ¿Está usted afiliado o } \\
\text { hace parte de una } \\
\text { asociación gremial o } \\
\text { sindical? } *\end{array}$ & 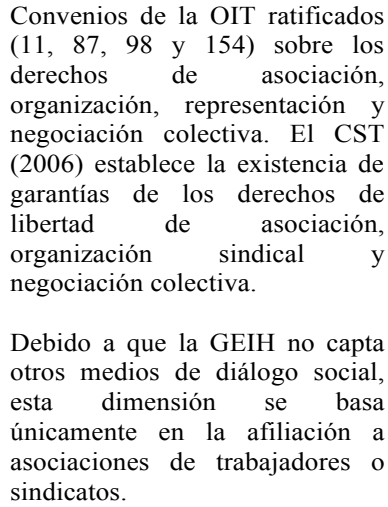 \\
\hline
\end{tabular}

Dado el contexto de los sindicatos y asociaciones de trabajo en Colombia, los trabajadores pueden no estar sindicalizados debido a varias razones. Es posible que no estén interesados, no puedan encontrar una asociación representativa, pueden tener miedo de afiliarse a un sindicato, no pueden afiliarse por el tipo de contrato o pueden estar coaccionados por el empleador para no hacerlo (PGN, 2011). Infortunadamente, los datos de la GEIH no permiten la identificación de estos detalles.

Fuente: autora

\section{Cálculo}

Con base en la literatura presentada en la sección Conceptos y dimensiones y siguiendo las recomendaciones de Muñoz et al. (2011), las cinco dimensiones de la precariedad laboral se consideran igualmente relevantes; por lo tanto, se les asignan pesos equivalentes en el cálculo del ITP. Del mismo modo, las variables que componen cada dimensión se ponderan de manera proporcional. El ITP entonces adiciona el valor de las nueve variables ponderadas de la siguiente manera:

$$
\begin{aligned}
& \operatorname{ITP}_{i}=0.067 \mathrm{X}_{11}+0.067 \mathrm{X}_{12,}+0.067 \mathrm{X}_{13}+0.10 \mathrm{X}_{21}+0.10 \mathrm{X}_{22}+0.20 \mathrm{X}_{31}+0.067 \mathrm{X}_{41} \\
& +0.067 \mathrm{X}_{42,}+0.067 \mathrm{X}_{43}+0.20 \mathrm{X}_{51}(2)
\end{aligned}
$$

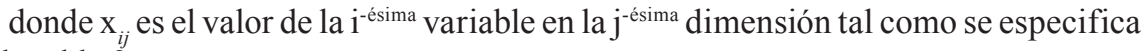
en la tabla 2.

Esta operacionalización es un estudio exploratorio a nivel individual. El ITP puede ser computado para cualquier tipo de trabajo, sea este empleo asalariado o independiente. Incluso, el ITP ofrece la posibilidad de incluir en el cálculo a aquellos trabajadores ocupados en actividades agropecuarias que, por lo general, no son tomados en cuenta en las medidas de informalidad. 


\section{Resultados principales}

\section{Incidencia de la precariedad}

Las estadísticas descriptivas del ITP y los indicadores correspondientes se presentan en la tabla 3. Tanto el índice como los indicadores adquieren valores entre 0 y 100. Los valores más cercanos a 0 señalan la situación de los trabajadores que sufren un mayor grado de precariedad, mientras que los valores más cercanos a 100 indican que los trabajadores gozan de condiciones de trabajo más seguras o de mejor calidad.

Algunos resultados merecen destacarse. En primer lugar, se puede ver que, en promedio, los mayores riesgos que enfrentan los trabajadores colombianos están en las dimensiones diálogo social y participación; seguridad y protección social; y seguridad de los ingresos. Este resultado es consistente con McKay et al. (2012). De otro lado, las condiciones de seguridad en el trabajo es la dimensión en la que los trabajadores se enfrentan a menores riesgos. En segundo lugar, todas las dimensiones y variables están distribuidas de forma asimétrica. Las variables provisión de pensiones, asociación al seguro de riesgos laborales, beneficios y prestaciones laborales, y sindicalización o asociación laboral muestran que son más los trabajadores que experimentan déficits que los que no, mientras que las variables asociación a la seguridad social en salud, ingresos laborales, estabilidad, seguridad en el lugar de trabajo y horas semanales de trabajo muestran la tendencia opuesta.

Tabla 3. Dimensiones y variables estadísticas descriptivas del ITP

\begin{tabular}{|c|c|c|c|c|}
\hline Dimensión & Variables & Media & $\begin{array}{c}\text { Desviación } \\
\text { estándar }\end{array}$ & Asimetría \\
\hline \multirow{4}{*}{$\begin{array}{l}\text { Seguridad y } \\
\text { protección } \\
\text { social }\end{array}$} & Asociación a la seguridad social en salud & 88.7 & 31.7 & -2.45 \\
\hline & Provisión de pensiones & 39.5 & 47.1 & 0.38 \\
\hline & Asociación al seguro de riesgos laborales & 28.8 & 45.3 & 0.94 \\
\hline & Dimensión 1 & 52.3 & 30.9 & 0.46 \\
\hline \multirow{3}{*}{$\begin{array}{l}\text { Seguridad de los } \\
\text { ingresos }\end{array}$} & Ingresos laborales & 64.8 & 36.7 & -0.39 \\
\hline & Beneficios y prestaciones laborales & 38.2 & 42.1 & 0.48 \\
\hline & Dimensión 2 & 52.0 & 33.9 & 0.09 \\
\hline Estabilidad & Estabilidad - Dimensión 3 & 74.8 & 28.0 & -0.85 \\
\hline \multirow{3}{*}{$\begin{array}{l}\text { Condiciones de } \\
\text { trabajo seguras } \\
\text { y dignas }\end{array}$} & Seguridad del lugar de trabajo & 74.4 & 24.2 & -0.10 \\
\hline & Horas semanales de trabajo & 76.2 & 28.7 & -0.50 \\
\hline & Dimensión 4 & 75.3 & 19.8 & -0.26 \\
\hline $\begin{array}{l}\text { Diálogo social y } \\
\text { participación }\end{array}$ & $\begin{array}{l}\text { Sindicalización o asociación laboral } \\
\text { Dimensión } 5\end{array}$ & 2.5 & 15.7 & 6.04 \\
\hline ITP & Índice de Trabajo Precario & 51.3 & 16.9 & 0.34 \\
\hline
\end{tabular}

Fuente: autora. 


\section{Distribución del trabajo precario}

De acuerdo con la conceptualización multidimensional de la precariedad, esta puede surgir en diversos grados y diversas formas en cualquier empleo, independientemente de la categoría ocupacional (Vosko et al., 2009). Como se muestra en la figura 2, el ITP cuando se construye a nivel individual permite identificar la extensión de la precariedad en todo el mercado laboral en diferentes grados. Dado que el ITP es un índice continuo, los resultados a continuación se presentarán organizados en tres niveles generales de precariedad: alto, medio, bajo. Como puede observarse, el 45,4\% de los trabajadores colombianos experimentó condiciones de alta precariedad del empleo en 2011 , mientras que solo un pequeño grupo $(10,3 \%)$ disfrutó de alta seguridad relacionada con el trabajo. El 44,3\% restante se ubica en una situación media de precariedad, una situación difícil de determinar en el sentido que solo el $9 \%$ de ellos están situados en la mediana de la distribución, mientras que el $21,1 \%$ es más vulnerable a experimentar condiciones precarias y el $14.2 \%$ está más cerca del disfrute de una alta seguridad laboral.

Figura 2. Distribución de la precariedad laboral en Colombia

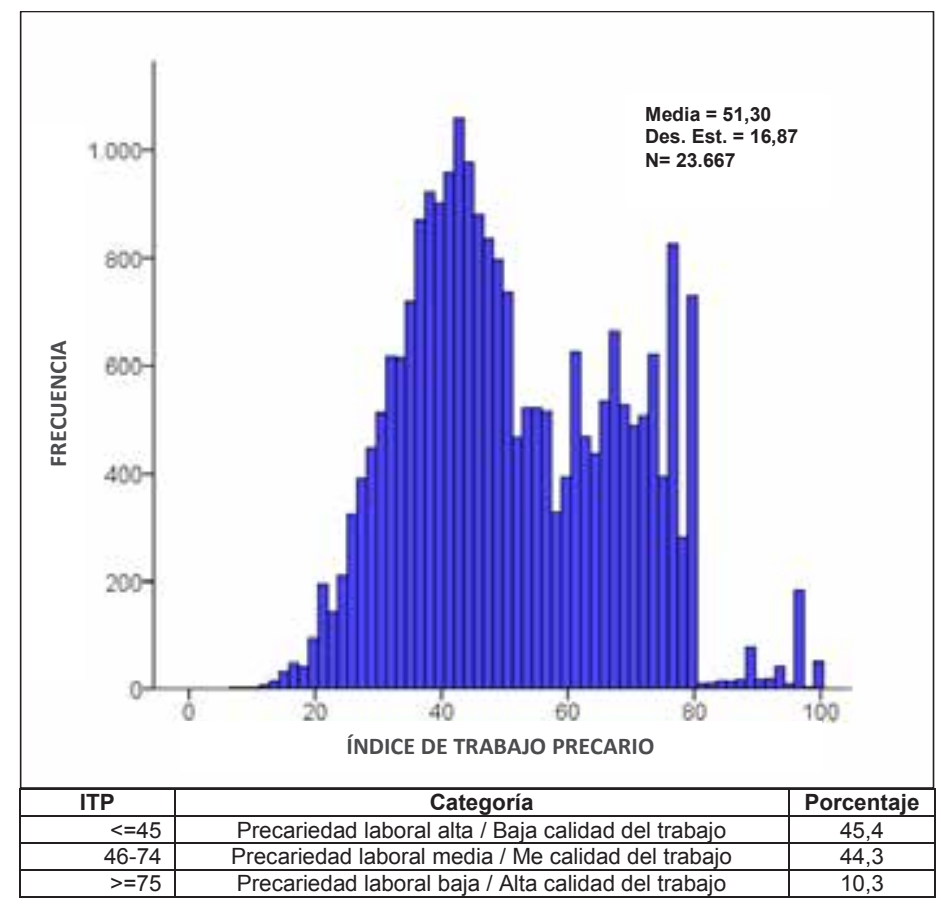

Fuente: autora. 


\section{Relación entre la informalidad y la precariedad}

Como se explica en la sección Conceptos y medición del trabajo informal, la posición ocupacional y el tamaño de la empresa son los criterios predominantes para identificar el empleo informal en Colombia. Por tanto, es conveniente analizar la distribución de la precariedad laboral a lo largo de dichas categorías para discutir el grado de precisión de la noción de informalidad del DANE en la identificación de la calidad del empleo.

En la figura 3 se examina hasta qué punto la precariedad y la informalidad difieren o se intersectan en el mercado laboral colombiano, con base en el ITP y el indicador de empleo informal del DANE. Esta figura muestra que el vínculo directo que se asume entre mejor calidad del trabajo y el empleo formal no está soportado empíricamente. Existe un grupo importante de trabajadores formales que experimentan diversos grados de precariedad laboral; 20,8\% de ellos están claramente ubicados en altos niveles de precariedad, debido principalmente a los déficits que enfrentan en términos de participación y representación colectiva, beneficios y prestaciones laborales y, provisión de pensiones. En contraste, apenas el $21,8 \%$ de los empleados formales mantienen puestos de trabajo de alta calidad en términos de seguridad. De otro lado, en el empleo informal parece ser muy poco probable encontrar puestos de trabajo de alta calidad; solo el 1,1\% de los trabajadores informales disfrutan de buenas condiciones laborales, mientras que el 59,5\% se ven afectados por la alta precariedad, especialmente en lo relacionado con la seguridad del ingreso y la representación colectiva de los trabajadores.

Figura 3. Distribución de la precariedad en el empleo formal/informal

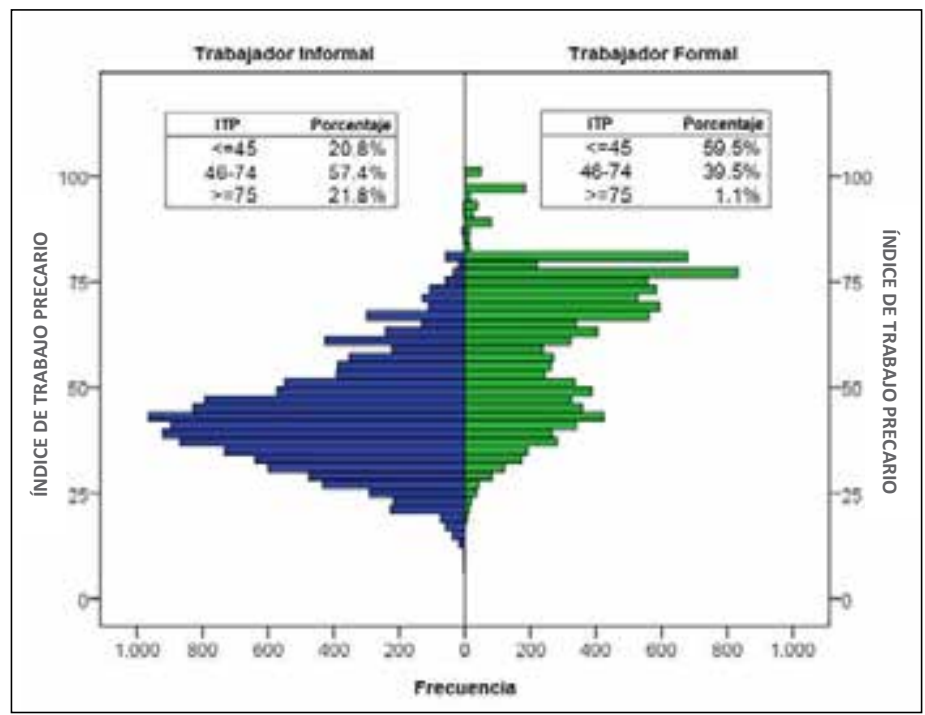

Fuente: autora. 
Si se extiende este análisis con mayor detalle a las diferentes categorías ocupacionales que son clasificadas como formales o informales por el DANE, tal como muestra la figura 4, puede notarse lo siguiente. Primero, la noción de empleo informal medido en Colombia es muy precisa en la identificación de la precariedad o calidad baja del empleo entre los trabajadores no remunerados, empleados domésticos y jornaleros o peones, ya que estas categorías ocupacionales muestran condiciones de precariedad muy altas. Al contrario, la informalidad no es la idea más precisa para distinguir el nivel de calidad del empleo en las demás categorías ocupacionales. Los casos que más resaltan son los trabajadores profesionales independientes y los trabajadores independientes, empleados y empleadores en grandes o medianas empresas, en cuyos casos apenas 1\%, 11\%, 23\% y 13\% disfrutan de empleo de alta calidad, respectivamente. Entre estos, el caso más preocupante es el de los trabajadores profesionales independientes, de los cuales un $50 \%$ se ve expuesto a condiciones altamente precarias de empleo a pesar de ser considerados trabajadores formales. Así mismo, empleadores de pequeñas empresas y trabajadores por cuenta propia no profesionales no aparecen estrictamente como categorías ocupacionales de alta precariedad; especialmente los pequeños empresarios entre los cuales solo el 14\% enfrentó condiciones precarias de empleo durante el año 2011. Igualmente, cabe mencionar que entre los empleados y empleadores de pequeñas empresas es posible reconocer $8 \%$ y $7 \%$ de trabajadores respectivamente que gozan de condiciones de trabajo altamente seguras. Finalmente, es notorio que el empleo en el sector formal es mucho más heterogéneo en términos de seguridad y calidad del trabajo, ya que los grupos intermedios son más representativos.

Figura 4. Distribución de la precariedad entre las categorías ocupacionales del empleo formal/informal

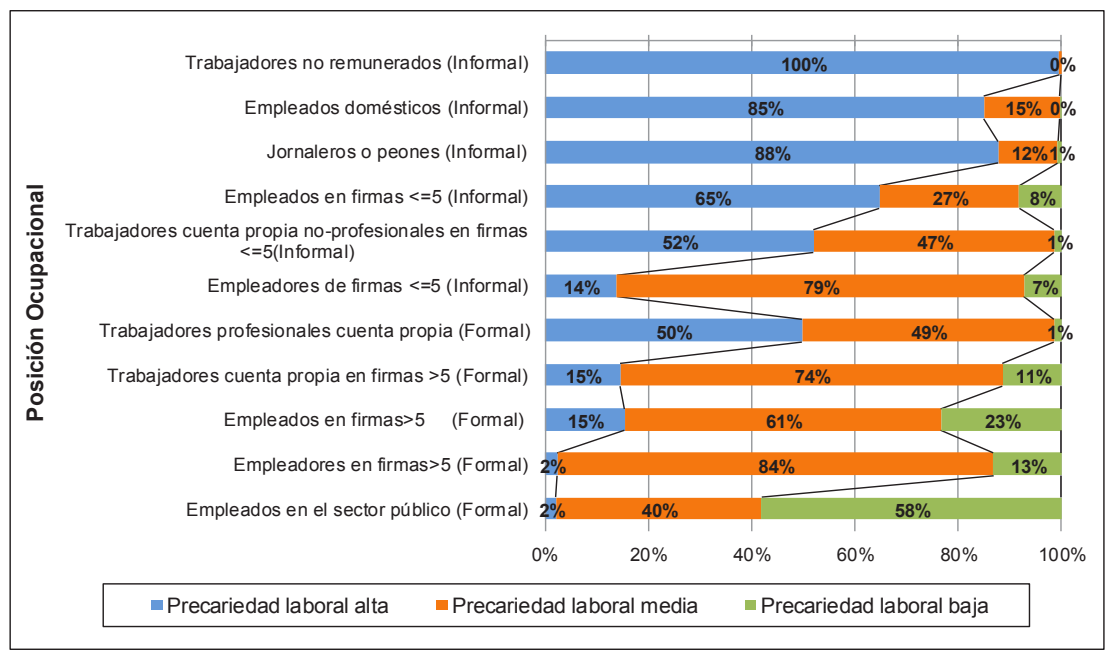

Fuente: autora. 
En la misma línea de ideas, la tabla 4 evalúa la precisión de la informalidad para identificar la calidad del empleo, con base en el criterio del tamaño de las empresas. Como puede verse, el $25,5 \%$ de la mano de obra que enfrenta condiciones de trabajo altamente precarias se compone de asalariados en empresas con más de cinco empleados (clasificados como empleo formal), mientras que el 36,2\% del empleo altamente seguro incluye trabajadores independientes en empresas de hasta cinco empleados (considerado como trabajo informal).

Tabla 4. La precariedad laboral y el tamaño de la empresa

\begin{tabular}{|c|c|c|c|c|c|c|}
\hline \multirow{2}{*}{\multicolumn{3}{|c|}{$\begin{array}{l}\text { \% dentro del Índice de } \\
\text { Trabajo Precario }\end{array}$}} & \multicolumn{3}{|c|}{ Índice de Trabajo Precario } & \multirow{2}{*}{ Total } \\
\hline & & & $<=45$ & $46-74$ & $\Rightarrow 75$ & \\
\hline \multirow{3}{*}{ Asalariados } & Tamaño de & $=<5$ & 74.5 & 16.3 & 3.2 & 32.7 \\
\hline & la firma & $>5$ & 25.5 & 83.7 & 96.8 & 67.3 \\
\hline & Total & & 100.0 & 100.0 & 100.0 & 100.0 \\
\hline \multirow{3}{*}{ Cuenta propia } & Tamaño de & $=<5$ & 97.2 & 86.1 & 36.2 & 90.2 \\
\hline & la firma & $>5$ & 2.8 & 13.9 & 63.8 & 9.8 \\
\hline & Total & & 100.0 & 100.0 & 100.0 & 100.0 \\
\hline
\end{tabular}

Fuente: autora.

Se llevaron a cabo test de correlación para averiguar si existe dependencia estadística entre el ITP y i) trabajo por cuenta propia, ii) empleo informal, iii) tamaño de la empresa $>5$, y iv) empleo formal (tabla 5). Aunque ninguna de las cuatro variables está fuertemente correlacionada con el ITP, todas las correlaciones son estadísticamente significativas. Esto sugiere que el empleo por cuenta propia, las pequeñas empresas y el trabajo informal no reflejan toda la extensión de la precariedad, ya que no son determinantes concluyentes del trabajo precario. 
Tabla 5. Pruebas de correlación entre el ITP y variables seleccionadas

\begin{tabular}{lcccc}
\multicolumn{1}{c}{ Test de correlación } & Valor & $\begin{array}{c}\text { Error Est. } \\
\text { Asint. }^{\text {a }}\end{array}$ & $\begin{array}{c}\text { T } \\
\text { Approx. }\end{array}$ & $\begin{array}{c}\text { Sig. } \\
\text { Approx. }\end{array}$ \\
\hline $\begin{array}{l}\text { Ordinal - Correlación ordinal } \\
\text { Spearman }\end{array}$ & -0.285 & 0.006 & -45713 & $0.000^{\text {c }}$ \\
$\begin{array}{l}\text { ITP / Categoría ocupacional cuenta } \\
\text { propia }\end{array}$ & & & & \\
$\begin{array}{l}\text { Intervalo - R, Intervalo Pearson } \\
\begin{array}{l}\text { ITP / Categorías ocupacionales del } \\
\text { empleo informal }\end{array}\end{array}$ & 0.417 & 0.005 & 70519 & $0.000^{\text {c }}$ \\
$\begin{array}{l}\text { Ordinal - Correlación ordinal } \\
\text { Spearman }\end{array}$ & 0.507 & 0.005 & 90536 & $0.000^{\text {c }}$ \\
$\begin{array}{l}\text { ITP / Tamaño de la firma }>5 \\
\begin{array}{l}\text { Ordinal - Correlación ordinal } \\
\text { Spearman }\end{array}\end{array}$ & 0.444 & 0.005 & 76321 & $0.000^{\text {c }}$ \\
$\begin{array}{l}\text { ITP / Empleo formal } \\
\text { N de observaciones válidas }\end{array}$ & 23667 & & & \\
\hline
\end{tabular}

Fuente: autora.
a. Sin asumir la hipótesis nula.
b. Usando el error estándar asintótico, asumiendo la hipótesis nula.
c. Basado en aproximación normal.

Algunos hallazgos importantes ayudan a explicar esta heterogeneidad:

i) Alrededor del 50\% de los profesionales independientes y $15 \%$ de los trabajadores por cuenta propia en empresas con más de cinco empleados mantienen empleos de baja calidad, debido esencialmente a graves deficiencias en las dimensiones de representación colectiva y seguridad de los ingresos.

ii) $70.1 \%$ de los trabajadores independientes experimentan alta seguridad laboral en términos de estabilidad, mientras que solo el $41 \%$ de los asalariados experimentan la misma condición. Esto está especialmente influenciado por la proporción de contratos temporales entre los asalariados $(38,5 \%)$ y la gran proporción de independientes, en su mayoría empleadores, que consideran que sus trabajos son permanentes $(80,5 \%)$.

iii) Solo el 20,6\% de los trabajadores asalariados mantienen empleos altamente seguros mientras que menos del 50\% de trabajadores autónomos son identificados como altamente precarios. 27,9\% de los asalariados 
experimentan altos riesgos en la dimensión de ingresos, especialmente en materia de prestaciones laborales (40,6\%), mientras que el $22,4 \%$ de los trabajadores por cuenta propia disfrutan de la situación contraria, particularmente respecto a altos ingresos $(36,5 \%)$.

iv) Los trabajadores independientes no profesionales y empleadores de pequeñas empresas no experimentan estrictamente alta precariedad. Solo el $14 \%$ de los últimos enfrentaron empleo de baja calidad, debido principalmente a la alta seguridad de los ingresos.

En resumen, la figura 5 ilustra los porcentajes precisos de intersección y distinción entre el trabajo precario y el empleo informal para el caso de Colombia en 2011 . Por consiguiente, en 2011 el mercado laboral colombiano estuvo compuesto por un $58,4 \%$ de empleo informal del cual $36,6 \%$ correspondió a trabajo altamente precario o de baja calidad, y $41,6 \%$ de empleo formal del cual el $8,3 \%$ concernió a trabajo altamente inseguro.

Figura 5. Intersección y distinción de la precariedad y la informalidad

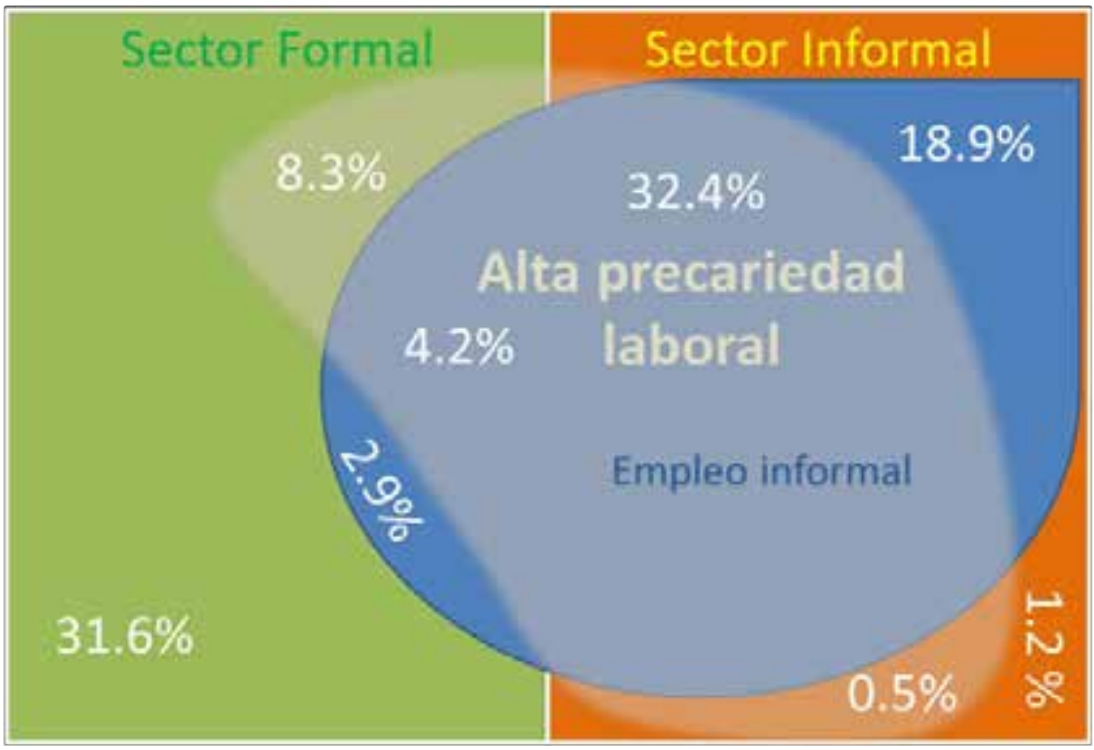

Fuente: autora.

6 Teniendo en cuenta que la medición del DANE no capta la diferencia entre el empleo en el sector informal y el empleo informal, el cálculo de esa distinción en la figura 4 se basó en el criterio del tamaño de la empresa, siguiendo el método de la OIT, como se muestra en la tabla 1. 
Todo lo anterior sugiere que la conceptualización y medición de la calidad del empleo a través de la informalidad conduce tanto a subestimación como sobreestimación de su prevalencia en Colombia. Primero, subestimación en el sentido que algunos trabajadores son clasificados como formales con base en criterios unidimensionales rígidos, aunque algunos de ellos están expuestos a alta precariedad laboral en uno o más aspectos. Segundo, sobreestimación porque a pesar de que la mayoría de los trabajadores informales se enfrentan a altos niveles de inseguridad y precariedad laboral, hay otros que alcanzan en algunos grados buenas condiciones de calidad del trabajo. En conclusión, se ha demostrado empíricamente la heterogeneidad en términos de la calidad del trabajo dentro de las categorías de empleo y economía formal/informal para el caso de Colombia, tal y como ha sido sugerido conceptualmente por Tucker (2002), Kucera y Roncolato (2008), Yussuf (2011), Williams y Nadin (2012) y la OIT (2012c).

\section{Conclusiones}

En este trabajo se demuestra que la definición y medición del empleo informal vigentes en Colombia siguen siendo insuficientes para revelar los distintos niveles de calidad y seguridad en el empleo. La informalidad no informa adecuadamente sobre las dificultades laborales que enfrentan los trabajadores en términos de precariedad; ni tampoco proporciona los criterios adecuados para la formulación de políticas. No obstante, la noción de precariedad laboral ofrece una mejor alternativa para comprender los distintos tipos de inseguridades laborales que son ignorados en el concepto de informalidad.

Como respuesta, este trabajo propone y operacionaliza una adaptación de la noción multidimensional de la precariedad laboral en el contexto de Colombia. En general, este trabajo concluye que la informalidad no refleja toda la extensión de la precariedad. Por tanto, es un error equiparar el empleo formal con empleo de buena calidad y el empleo informal con empleo de mala calidad. Lo anterior porque la prevalencia de la precariedad traspasa los límites de la dicotomía formal/informal, como ha sido sugerido conceptualmente en el debate académico por autores como Tucker (2002), Kucera y Roncolato (2008), Yussuf (2011), Williams y Nadin (2012) y la OIT (2012c).

En este artículo se demuestra empíricamente la heterogeneidad en términos de la calidad del trabajo dentro de las categorías de empleo y economía formal/informal en el caso específico de Colombia. Los resultados sugieren que los principales déficits en la calidad del trabajo que afronta la fuerza laboral colombiana son en materia de participación y representación colectiva, protección contra riesgos laborales, beneficios y prestaciones laborales, y provisión de pensiones. En consecuencia, las políticas sobre la calidad del empleo deben integrarse mejor dentro de las estrategias 
de desarrollo del país, con el fin de vincular las acciones económicas y sociales con el entorno regulatorio institucional. Al respecto, este estudio sugiere tres elementos importantes para tener en cuenta en dicha agenda política:

i) La exclusión evidente de los trabajadores cuenta propia de la legislación laboral vigente, la cual solo aplica para el trabajo subordinado o asalariado. La gestión de marcos institucionales para la regulación de condiciones de empleo segura y digna para los trabajadores independientes sigue siendo una agenda pendiente.

ii) Se requieren acciones precisas en materia de seguridad laboral dirigidas a los trabajadores de las zonas rurales, que generalmente son ignorados en las mediciones de informalidad y se evidencian claramente más vulnerables a la precariedad.

iii) Dado el enorme déficit de representación colectiva de los trabajadores en Colombia, resulta crucial innovar en acciones legales y prácticas para la promoción de oportunidades de participación y representación más inclusivas a todas las formas de trabajo. Como lo afirma la OIT (2013c), la promoción del diálogo social y la participación colectiva son decisivas para reducir el empleo precario.

Todo lo anterior implica que las políticas relativas a la calidad del trabajo exigen su propio lugar en la agenda política del país, no solo como un tema secundario subordinado a otros objetivos como el crecimiento del PNB, la competitividad y la formalización de las empresas. Para ello es necesario introducir nuevos conceptos y medidas de precariedad laboral, como los aquí propuestos, que permitan capturar información más relevante para los hacedores de política sobre los desafíos de la calidad del empleo en el país.

Por último, esta propuesta de conceptualización y operacionalización de la precariedad del trabajo requiere de mayores desarrollos teniendo en cuenta sus virtudes y limitaciones. Esta es un área de investigación pionera que incentiva estudios futuros sobre la naturaleza particular de la precariedad laboral en países en desarrollo. Del mismo modo, futuras investigaciones pueden abordar la evaluación de la noción de precariedad en línea con otros conceptos introducidos por la OIT en materia de estudios del mercado laboral, tales como trabajo decente y trabajo vulnerable. Estas son solo algunas de las posibilidades que se abren a la investigación con el interés de fomentar acciones políticas para mejorar las condiciones de empleo en el contexto de los países en desarrollo.

\section{Referencias}

Arnold, D. y Bongiovi, J. (2012). Precarious, informalizing and flexible work: Transforming concepts and understandings. American Behavioral Scientist, 57(3), 1-20. 
Bacchetta, M., Ekkehard, E. y Bustamante, J. (2009). Globalization and informal jobs in developing countries. Ginebra: OIT.

Banco de la República (2011). Informe del Banco de la República al Congreso Nacional. Bogotá: Banco de la República.

Barbier, J.C., Brygoo, A., y Viguier, F. (2002). A tentative approach to precarious employment in France. ESOPE Project Report, FP 5. Paris: Centre d'études de l'emploi, Noisy-le-Grand.

Biles, J. (2009). Informal work in Latin America: Competing perspectives and recent debates. Geography Compass, 3(1), 214-236.

Botero, J. (2011). Desempleo e informalidad en Colombia. Un modelo de equilibrio general computable. Ponencia presentada en Seminario Semanal de Economía, 12 de agosto, Banco de la República.

Campbell, I., Whitehouse, G. y Baxter, J. (2009). Australia: Casual employment, parttime employment and the resilience of the male-breadwinner model. In L. Vosko, M. MacDonald y I. Campbell (Eds.). Gender and the contours of precarious employment (pp. 60-75). Nueva York: Routledge.

Chen, M. (2007). Rethinking the informal economy - linkages with the formal economy and formal regulatory environment. UN-DESA Research Paper N ${ }^{\circ} 46$.

Comisión Económica para América Latina y el Caribe - CEPAL. (2011). Anuario Estadístico de América Latina y el Caribe. Santiago de Chile: CEPAL.

Constitución Política de Colombia. (1991). http://confinder.richmond.edu/admin/ docs/colombia_const2.pdf, último acceso 28 de septiembre de 2014.

Consejo Privado de Competitividad - CPC. (2010). Informe Nacional de Competitividad. Bogotá: CPC.

Departamento Administrativo Nacional de Estadística - DANE. (2009). Metodología informalidad, encuesta integrada de hogares. Bogotá: DANE.

De Soto, H. (1989). The other path. The invisibly revolution in the third world. Nueva York: Harper and Row.

Departamento Nacional de Planeación - DNP. (2011). Plan Nacional de Desarrollo 2011- 2014: Prosperidad para todos. Bogotá: DNP.

European Commission. (2004). Precarious employment in Europe: A comparative study of labour market related risks in flexible economies. Informe Final. Bruselas: EU Research on Social Sciences and Humanities.

Farné, S., Vergara, C. y Baquero, N. (2011). La calidad del empleo en medio de la flexibilización laboral. Bogotá: Universidad Externado de Colombia. 
Fields, G. (1990). Labour market modelling and the urban informal sector: Theory and evidence. En D. Turnham, B. Salomé y A. Schwarz (Eds.). The informal sector revisited (pp. 49-69). París: OECD.

Habib-Mintz, N. (2009). To what extent can the informal economy concept adequately explain the dynamism of the non-formal sector in developing countries? Journal of International Business and Economy, 10(1), 1-19.

Hussmanns, R. (2004). Defining informal employment and methodologies for its measurement - statistical definition of informal employment: Guidelines endorsed by the Seventeenth International Conference of Labour Statisticians. Ginebra: OIT.

International Trade Union Confederation. (2014) Survey of violations of trade union rights, http://survey.ituc-csi.org/Colombia.html?lang=en\#tabs-2. Último acceso 15 de julio de 2014.

Kucera, D. y Roncolato, L. (2008). Informal employment: two contested policy issues. International Labour Review, 147(4), 321-348.

MacInnes, J. (2009). Spain: Continuity and change in precarious employment. In L. Vosko, M. MacDonald y I. Campbell (Eds.). Gender and the contours of precarious employment (pp. 159-176). Nueva York: Routledge.

McKay, S., Jefferys, S., Paraksevopoulou, A. y Keles, J. (2012). Study on precarious work and social rights. Informe Final a la Comisión Europea. Londres: London Metropolitan University.

Muñoz, R., Fernández, E., Esteve, F. y Antón, J. (2011). E Pluribus Unum? A Critical Survey of Job Quality Indicators. Socio-Economic Review, 9(3), 447-475.

Organización Internacional del Trabajo - OIT. (2002). Effect to be given to resolutions adopted by the International Labour Conference at its 90th Session (2002), (b) Resolution concerning decent work and the informal economy. Ginebra: OIT.

Organización Internacional del Trabajo - OIT. (2004). Seguridad económica para un mundo mejor. Ginebra: OIT.

Organización Internacional del Trabajo - OIT. (2006). Trabajo decente en las Américas: una agenda hemisférica, 2006-2015. Informe del Director General a la XVI Reunión Regional Americana. Ginebra: OIT.

Organización Internacional del Trabajo - OIT. (2012a). Statistical update on employment in the informal economy. Ginebra: OIT.

Organización Internacional del Trabajo - OIT. (2012b). Del trabajo precario al trabajo decente. Documento final del Simposio de los Trabajadores sobre Políticas de Reglamentación para Luchar contra el Empleo Precario. Ginebra: OIT. 
Organización Internacional del Trabajo - OIT. (2012c). Sistema de Información sobre Estándares Internacionales de Trabajo. Ratificaciones de Colombia, http://www. ilo.org/dyn/normlex/en/f?p=1000:11200:0::NO::P11200_COUNTRY_ID:102595. Último acceso 30 de junio de 2014.

Organización Internacional del Trabajo - OIT. (2013a). La medición de la informalidad: Manual estadístico sobre el sector informal y el empleo informal. Ginebra: OIT.

Organización Internacional del Trabajo - OIT. (2013b). Statistics of work and of the labour force. Report for discussion at the Meeting of Experts in Labour Statistics on the advancement of employment and unemployment statistics. Ginebra: OIT.

Organización Internacional del Trabajo - OIT. (2013c). Meeting the challenge of precarious work: A workers' agenda. International Journal of Labour Research, 5(1), 5-168.

Pineda, J. (2008). Informalidad y calidad de empleo. En C. López, L. López, J. Pineda, S. Vanegas (Eds.). Vías y escenarios de la transformación laboral: aproximaciones teóricas y nuevos problemas (pp. 281-306). Bogotá: Universidad del Rosario.

Procuraduría General de la Nación. (2011). Trabajo digno y decente en Colombia: Seguimiento y control preventivo a las políticas públicas. Bogotá: Procuraduría General de la Nación.

República de Colombia. (1950). Código Sustantivo del Trabajo de Colombia - CST (última actualización 2006), http:// http://www.ilo.org/dyn/travail/docs/1539. Último acceso 30 de marzo de 2013.

Rodgers, G. y Rodgers, J. (1989). Precarious jobs in labour market regulation: The growth of atypical employment in Western Europe. Ginebra: OIT.

Sindzingre, A. (2006). The relevance of the concepts of formality and informality: A theoretical appraisal. In G. Khasnobis, R. Kanbur y E. Ostrom (Eds.). Linking the formal and informal economy: Concepts and policies (pp.1-26). Oxford: Oxford University Press.

Standing, G. (2011). The precariat: The new dangerous class. Nueva York: Bloomsbury Academic.

Standing, G. (1999). Global labour flexibility: Seeking distributive justice. Nueva York: St. Martin's Press.

Taylor, R. (2004). Extending conceptual boundaries: Work, voluntary work and employment. Work, Employment and Society, 18(1), 29-49.

Tucker, D. (2002). Precarious non-standard employment - a review of the literature. Working Paper. Department of Labour - Government of New Zealand. 
Vosko, L. (2006). Precarious employment: Towards an improved understanding of labour market insecurity. In L. Vosko (Ed.). Precarious employment: Understanding labour market insecurity in Canada (pp. 3-39). Montreal: McGillQueen's University Press.

Vosko, L. (2006b). What is to be done? Harnessing knowledge to mitigate precarious employment. In L. Vosko (Ed.). Precarious employment: Understanding labour market insecurity in Canada (pp. 379-388). Montreal: McGill-Queen's University Press.

Vosko, L. and Clark, L. (2009). Canada: Gendered precariousness and social reproduction. In L. Vosko, M. MacDonald y I. Campbell (Eds.). Gender and the contours of precarious employment (pp. 26-41). Nueva York: Routledge.

Vosko, L., MacDonald, M. y Campbell, I. (2009). Gender and the concept of precarious employment. In L. Vosko, M. MacDonald y I. Campbell (Eds.). Gender and the contours of precarious employment (pp. 1-25). Nueva York: Routledge.

Williams, C. y Nadin, S. (2012). Work beyond employment: Representations of informal economic activities. Work, Employment and Society, 26(2), 1-10.

Yusuff, O. (2011). A theoretical analysis of the concept of informal economy and informality in developing countries. European Journal of Sciences, 20(4): 624. 